\title{
Research on the Spatial Distribution and Its Influencing Factors of China Provincial Innovation Output
}

\author{
Peng Wang, Shuoshuo Li \\ College of Economics, Jinan University, Guangzhou, China \\ Email: lessy0322@163.com
}

Received 14 April 2016; accepted 13 May 2016; published 16 May 2016

Copyright (C) 2016 by authors and Scientific Research Publishing Inc.

This work is licensed under the Creative Commons Attribution International License (CC BY). http://creativecommons.org/licenses/by/4.0/

c) (i) Open Access

\begin{abstract}
In recent years, due to the development of spatial econometrics, to study the innovation agglomeration with the view of space angle is attracting more attention. Based on 31 provinces in mainland China in 2004-2013 of the patent grant data using spatial econometric knowledge to analyze spatial agglomeration of innovation output, the results showed that: The innovation output is imbalance, the eastern coastal region innovation level is far greater than the Midwest, and the polarization phenomenon aggravates gradually; from the Moran's I index, innovation output is positive related in the space, and the geographical agglomeration phenomenon is not a random distribution, but there are specific rules; Durbin model shows that the area around the region has a significant impact on innovation output, and further calculates the strength of the influence of space effect. At last, this paper puts forward policy suggestions to improve innovation ability and make the balanced development of regional innovation.
\end{abstract}

\section{Keywords}

Innovation Agglomeration, The Number of Patent Grant, Spatial Durbin Model

\section{Introduction}

The concept of "innovation" is originated in "Introduction to Economic Development" published by the American economist Schumpeter in 1912. Schumpeter in his book stated: Innovation refers to the "new combination" of a new production factor and production conditions to introduce to the production systems. In the era of knowledge economy, innovation is the key of scientific and technological progress and the driving force of economic development. Therefore, the improvement of innovation ability is of great significance. China also at- 
taches great importance to innovation and puts forward to build innovative country from the twelfth five-year plan to eighth session of the National People's Congress. Therefore, innovation research factors have also been more and more attention. However, previous studies rarely involve innovative space concept. On the basis, this paper uses the spatial econometric methods to further study the innovative space distribution and its influencing factors.

Spatial Economic Theory (Anselin, 1988) holds that: A certain geographical phenomena on the regional economic space unit, or some property values on adjacent areas spatial units of the same phenomenon or attribute value is relevant, since the next position, resulting in the interaction space between the surface of things and phenomena and space spillover effect, and thus a certain spatial structure [1]. In terms of innovation activities, innovation output in a region is affected by both local innovation, economic level, the level of science and technology, institutional conditions and social and cultural factors, but also is closely related to the various elements of the surrounding neighborhood. Therefore, innovation output gathered in a particular region of spatial distribution. This is called spatial dependence or spatial correlation. It shows the consistency between the observations and the location, which means that specific location of the observation will be affected surrounding areas. Innovation output can be epitomized innovation capacity of a specific area. Therefore, this paper uses innovation output as the measuring indicators of innovation capability to describe and analyze spatial distribution characteristics of innovation. At the same time, the paper uses spatial econometric model to introduce the spatial concept to analyze the factors affecting the ability to innovate, in order to improve the ability to innovate and put forward policy recommendations for the regional innovation and balanced development.

\section{Theoretical Basis}

Endogenous growth theory thinks technological innovation as an important engine of economic development and the research of innovation has a long time. The traditional view regards the innovation process as a linear relationship between input and output. R\&D funding, R\&D investment and other factors can bring some innovation output [2]. This view exists two problems: first, too much emphasis is on the development process; the second is to be seen as entirely innovative production behavior. Modern innovative ideas view the innovation process in a more sociological perspective, as opposed to the traditional linear model, Kline and Rosenberg proposed interaction model [3]. The model assumes that numerous, repetitive feedback is an important source of innovation, and learning and collaboration are tools to generate feedback and interaction [4].

In recent years, some domestic scholars have studied the spatial distribution of innovative agglomeration. Their research for innovation cluster is divided into two areas: on the one hand, from the spatial distribution of innovation activities in this area we have a study to analyze the geographical agglomeration of innovation with geography knowledge; on the other hand, existing research study not only the distribution of innovation activities, but also the reason for the distribution. The general emphasis on the phenomenon of innovation concentration has produced the field of theoretical studies of innovative clusters. In this paper, the situation and findings of research status on several fields of innovative clusters, such as the concept and connotation of innovative clusters, the classification of innovative clusters, the influence factors and Formation Mechanisms of innovative clusters, the topological structure and evolution mechanism of innovative clusters, also the intersection and merging of innovative clusters with other Relevant Areas, have been commentated, Some concluding expositions on deficiencies and research trend of innovative clusters has been put forward (Song Qi, 2010) [5]. Jianji Zhao (2009) [6] attempts to review thoroughly the data and indicators economic geographer used in conducting a study on the spatial measurement of innovation, and pointed out the shortages. Based on these questions, as well as the new challenge which proposed to the existed data and indicators derive from the enterprise strategy alliance, this paper proposed that in the spatial measurement of innovation, we must consider the multi-dimensional economy, the society and the political background in which the innovation occurred, and unify the concept of learning region to construct the new analytical framework. Fengchao Liu, Yang Ling, and Yutao Sun (2011) [7] based on the overview of the foreign research in the spatial concentration o $\mathrm{f}$ innovation, this paper summarizes the success and the main problems of present researches, and then point s out the developing tendency in future study. Yuming Wu (2006) [8] used a spatial constant-coefficient regression model which is called Spatial Lag Model and Spatial Error Model, and spatial varying-coefficient regression model which is called geographically weighted regression of spatial econometric methods, a spatial econometric analysis on research and experimental development (R\&D) and innovation of China's 31 provincial regions is performed. 
Spatial econometric analysis is performed. The global estimation results discover that enterprise R\&D has contribution to the innovation capability of China's 31 provincial regions while university R\&D does no t contribute obviously to the provincial innovation capability. The combination of university and enterprise does no t have positive impact on innovation also. The local geographically weighed regression estimation results show that enterprise R\&D capability and human capital have positive impact on the provincial innovation competence. The spatial distribution pattern and regional structural characteristics of Chinese mainland innovative output are studied based on patent statistics on province level. Drawing on the average rate of industry focus areas and the indicator of market concentration, the results show that innovation concentrates in several provinces. In view of the spatial concentration characteristics of innovation output, we use Moran's I index to test the spatial autocorrelation which identifies whether the distribution of innovation agglomeration is random or deliberate $(\mathrm{Wu} \mathrm{Zi}$, 2010) [1]. By calculating the location quotient of the five high-tech industries and traditional manufacturing industries in China's regions, Lihua Zhang, Shanlang Lin (2010) [9] revealed spatial distribution of industrial innovation and production activities. Using spatial econometrics techniques, Li Jing (2013) [10] study the spatial integration features of Chinese region innovation based on data from 1998 to 2010 across 30 provinces in China. The theil entropy of output value, the Moran's I index and scatter plot indicate that it has inequality and integration of the development of the innovation among provinces. The spatial econometrics models of patent and contract amount indicate there are distinct correlation between the R \& D funds and the output value of patent and contract amount. The influence level of R\&D personnel investment and GDP to patent is remarkable, but it is not remarkable to contract amount. Models added factors of space prove the existence of spatial autocorrelation again, and its coefficient is given out [11]. Yuming Zhang, Li Kai (2008) [12] also think patent data as a measure indicator of innovation output and further noted a non-random distribution of Chinese provincial innovation output with Moran's I index showing different levels of innovation clusters and spatial dependence by using of Chinese mainland's 31 provinces patent data. Fayou Luo (2004) [13] found China's innovation output concentrated in the eastern coastal areas through the study of patent data. Han Jing (2013) [14] studied innovation efficiency of Chinese provinces in 2010 from green growth perspective by using of a four-stage DEA model including spatial econometrics.

The existing literature studied the spatial distribution of innovation outputs from two aspects: firstly, the existing literature analyzed innovation cluster index with spatial econometrics and gained the spatial dependence of innovation activities, but no empirical analysis; secondly, the existing literature carried on empirical analysis on the impact elements of innovation spatial distribution, but it did not explain the spatial distribution is generated randomly, or have a certain spatial correlation. Therefore, this paper analyzes the spatial distribution and autocorrelation of innovation output with 2004-2013 China's 31 mainland provinces data and study influencing factors of spatial autocorrelation of innovation output with spatial econometrics model to put forward policy recommendations.

\section{Spatial Distribution Characteristics of Innovation Output}

Figure 1 and Figure 2 show spatial distribution of patents granted of China in 2004 and 2013. Overall, the segment range from two graphs can be seen, patents granted in China's regions are on the rise from 2004 to 2013, but they have relatively large gap. The eastern has maximum number, central and western regions lagging behind. However, the each province has some changes in the decade: the number of patents in most of the southeast coastal areas is in the first grade, but Liaoning, Tianjin, Fujian slightly changed, the number of patents in Liaoning has a downward trend over the years, Tianjin rises from the third level up to the second level, but there is a gap with the first level in general, Fujian has been in second grade, lagging behind other coastal areas, the number of patents increased in Hubei, but decreased in Jilin, Tibet, Qinghai has been at the lowest level. Both figures reflect spatial distribution of innovation output in China and show degree of strength of innovation activities. Color more severe, the more innovation output, innovation ability is stronger, otherwise weaker.

Table 1 provides total overview of 10-year patent data in China. Table 1 may further be seen that nearly 10 years innovation mainly concentrated in the southeast coastal provinces. Compared with Yuming Zhang, Li Kai (2008), we can find in nearly 10 years Jiangsu has formed the largest innovation cluster instead of Guangdong. As can be seen from the cumulative percentage, the total number of patent in the top ten accounted for $80.25 \%$ of the total number of patents in China, cumulative percentage of the top five has exceeded half, accounting for $63.5 \%$, these two data of previous studies were $74.23 \%$ and $52.67 \%$. As it can be seen, the degree of innovation 


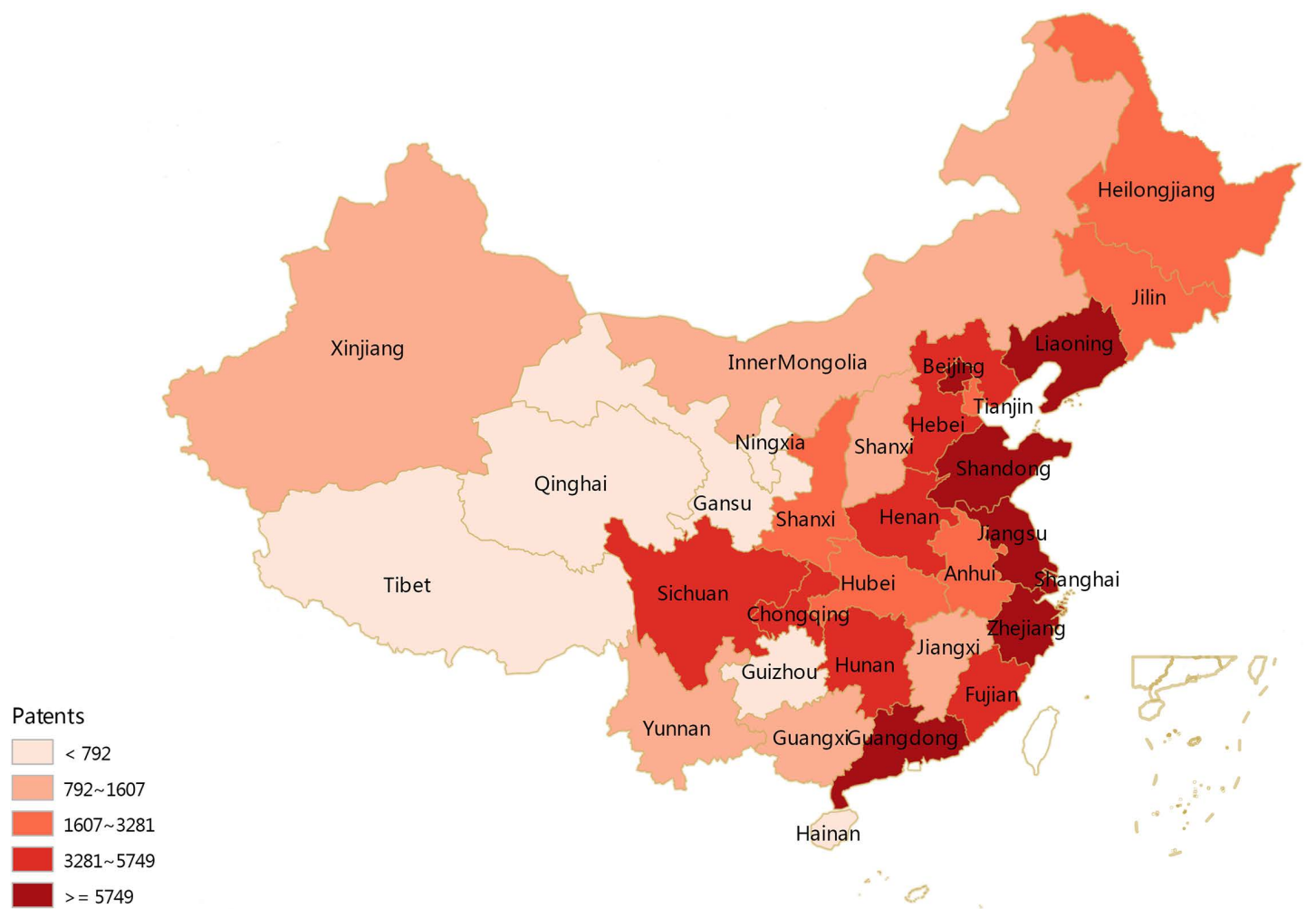

Figure 1. 2004 spatial distribution of patents granted. Data source: According to patents granted of 2004 "China Statistical Yearbook".

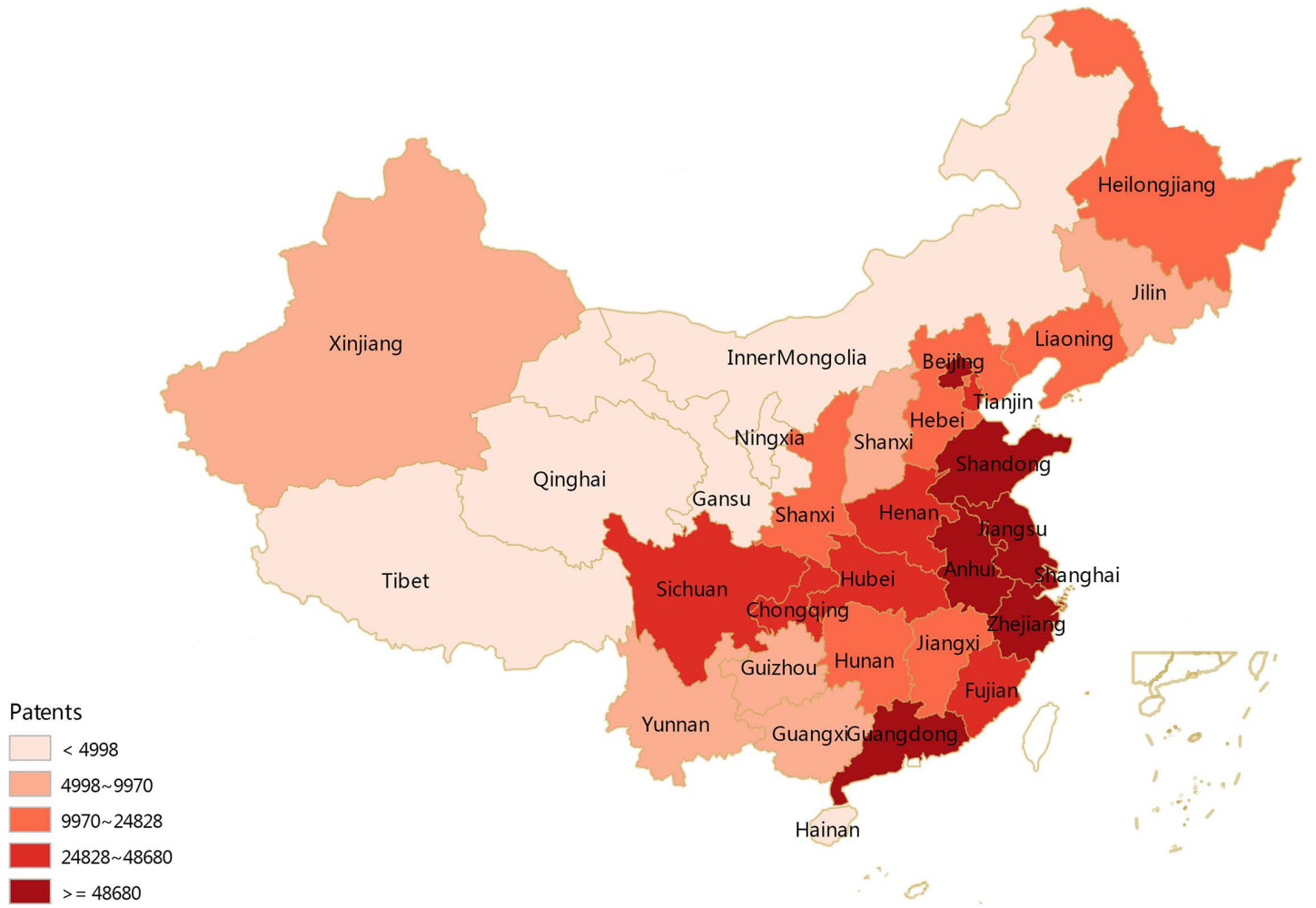

Figure 2. 2013 spatial distribution of patents granted. Data source: According to patents granted of 2013 "China Statistical Yearbook". 
Table 1. 2004-2013 patent statistics.

\begin{tabular}{cccccccccc}
\hline Ranking & Province & $\begin{array}{c}\text { The sum of } \\
10 \text { years }\end{array}$ & Percentage & $\begin{array}{c}\text { Cumulative } \\
\text { percentage }\end{array}$ & Ranking & Province & $\begin{array}{c}\text { The sum of } \\
10 \text { years }\end{array}$ & Percentage & $\begin{array}{c}\text { Cumulative } \\
\text { percentage }\end{array}$ \\
\hline 1 & Jiangsu & $1,055,541$ & 19.04 & 19.04 & 17 & Heilongjiang & 82,396 & 1.49 & 93.54 \\
2 & Guangdong & 885,743 & 15.98 & 35.02 & 18 & Shanxi & 77,744 & 1.40 & 94.94 \\
3 & Zhejiang & 875,886 & 15.80 & 50.82 & 19 & Jiangxi & 39,199 & 0.71 & 95.65 \\
4 & Shandong & 383,241 & 6.91 & 57.73 & 20 & Jilin & 37,013 & 0.67 & 96.32 \\
5 & Shanghai & 320,055 & 5.77 & 63.50 & 21 & Shanxi & 36,815 & 0.66 & 96.98 \\
6 & Beijing & 273,546 & 4.94 & 68.44 & 22 & Guangxi & 32,609 & 0.59 & 97.57 \\
7 & Sichuan & 208,657 & 3.76 & 72.20 & 23 & Yunnan & 32,044 & 0.58 & 98.15 \\
8 & Anhui & 162,997 & 2.94 & 75.14 & 24 & Guizhou & 28,984 & 0.52 & 98.67 \\
9 & Fujian & 151,225 & 2.73 & 77.87 & 25 & Xinjiang & 21,434 & 0.39 & 99.06 \\
10 & Henan & 131,935 & 2.38 & 80.25 & 26 & Inner Mongolia & 18,067 & 0.33 & 99.39 \\
11 & Liaoning & 130,969 & 2.36 & 82.61 & 27 & Gansu & 17,889 & 0.32 & 99.71 \\
12 & Hubei & 127,853 & 2.31 & 84.92 & 28 & Ningxia & 6358 & 0.11 & 99.82 \\
13 & Hunan & 110,218 & 1.99 & 86.91 & 29 & Hainan & 5896 & 0.11 & 99.93 \\
14 & Chongqing & 101,894 & 1.84 & 88.75 & 30 & Qinghai & 2895 & 0.05 & 99.98 \\
16 & Tianjin & 99,186 & 1.79 & 90.54 & 31 & Tibet & 1121 & 0.02 & 100 \\
\hline
\end{tabular}

Data Source: According to patents data of 2004-2013 “China Statistical Yearbook”.

concentration in recent years is gathering more and more strongly. Although the absolute values are on the rise overall, but the gap between the mid-west and southeast coastal areas is increasing, especially after the ten provinces in the country only to $3.02 \%$. This shows that the innovation exhibits the significant spatial polarization.

The main reason of this polarization phenomenon is the unbalance of regional economic development. The southeast coastal areas have unique geographical advantage. With the forefront of reform and opening, economic development of southeast coastal areas is rapid to lead to the influx of a lot of talent, so with the cumulative cycle, the development is better and better. The western region is in bad location. Although the policy support, it is difficult to retain talent, leading to further economic development backwardness, lack of innovation motivation.

\section{Spatial Correlation of Innovation Agglomeration}

The third part of the analysis describes that innovation output shows a significant geographic clustering features in the spatial distribution. To test innovation output agglomeration is immediately occur, or the presence of a specific distribution, this paper will carry on spatial correlation test of patent data. We use most commonly used indicators in spatial statistics, namely the value of Moran's I, to verify spatial correlation between innovation outputs. Spatial autocorrelation tests fall into two categories: first is the global spatial autocorrelation test, which calculates the 2004-2013 Moran's I value and its significance test; second is partial autocorrelation test. In this paper it is shown patents granted to the Moran scatter plot in 2004 and 3013 and further illustrates spatial distribution of innovation output between the various provinces.

\subsection{Moran's I Value Analysis of Global Spatial Autocorrelation Test}

Before calculating the value of Moran's I, we need to build a spatial weight matrix between the various prov- 
inces, that is $W_{i j}$, it defines the adjacent relationship between spatial objects. The general adjacent standard $W_{i j}$ is:

$$
W_{i j}= \begin{cases}1 & i \text { and } j \text { are neighbor } \\ 0 & i \text { and } j \text { are not neighbor }\end{cases}
$$

The definition of "adjacent" is commonly used in two ways: that is rook and queen (rook and queen are chess pawn, rook can only cross walk and go straight, but in addition to cross walk and go straight, queen can also move diagonally). In the "rook" standard, the adjacent cells must have a length than zero common borders; in the "queen" standard, the common border could just short or a point of the boundary. Therefore, queen-based space adjacent matrix often has more closely associated with surrounding areas (with more neighborhoods). Based on it is mostly made up of many highly irregular polygons of Chinese provinces boundary, this paper uses "queen" standard to judge whether the two areas are adjacent. It generates weight matrix using the first-order of queen in Geoda.

After generating weight matrix, we make it standardized, that is, the sum of each row element is 1 . Then we get the Moran's I formula with the standardized weight matrix: Moran's I $=\frac{\sum_{i=1}^{n} \sum_{j=1}^{n} W_{i j} \cdot\left(x_{i}-\bar{x}\right) \cdot\left(x_{j}-\bar{x}\right)}{\sum_{i=1}^{n}\left(x_{i}-\bar{x}\right)^{2}}, W_{i j}$ is the standardized weight matrix, $\bar{x}=\frac{1}{n} \sum_{i=1}^{n} x_{i}, x_{i}$ and $x_{j}$ are respectively the observations of geographical unit $i, j$.

It ranges between -1 to 1 of Moran's I value, usually interpreted as a spatial autocorrelation coefficient. At a given level of significance, through Z test, if Moran's I value is significantly positive, there is positive spatial autocorrelation, indicating the value of the same property together; if significant Moran's I value is negative, there is negative spatial autocorrelation, indicating the value of different properties together.

Table 2 shows the 2004-2013 spatial correlation coefficients and test results.

In Table 2, at the 5\% significance level, Moran's I values are positive and all through the test of significance. It indicates positive spatial autocorrelation in 2004-2013. Agglomeration phenomenon of innovation output is not randomly generated, but has a specific distribution. Spatial agglomeration of innovation output shows strong spatial dependence characteristics. Areas with higher level of innovation tend to be close to other areas with a higher level of innovation, and vice versa. From the specific values of the table, in addition to individual years, Moran's I value of innovation output is gradually increasing trend, indicating that spatial concentration pattern of innovation output continues to strengthen.

Table 2. 2004-2013 Moran's I value and test of patents granted.

\begin{tabular}{cccc} 
Time & Moran's I & Z-value & P-value \\
\hline 2004 & 0.343074 & 3.5532 & 0.001 \\
2005 & 0.350386 & 3.6181 & 0.001 \\
2006 & 0.335441 & 3.4810 & 0.001 \\
2007 & 0.33765 & 3.5100 & 0.002 \\
2008 & 0.349932 & 3.5562 & 0.002 \\
2009 & 0.383509 & 3.7558 & 0.001 \\
2010 & 0.384087 & 3.8458 & 0.001 \\
2011 & 0.408303 & 3.9359 & 0.001 \\
2012 & 0.402027 & 4.0358 & 0.001 \\
2013 & 0.388849 & 4.0069 & 0.001 \\
\hline
\end{tabular}

Note: At the $5 \%$ significance level, the $\mathrm{Z}$ threshold is 1.6449 . 


\subsection{Moran Scatter Plot Analysis of Partial Spatial Autocorrelation Test}

Global Moran's I index reveals the presence of innovation agglomeration in China. However, to analyze the innovation level of every province in China, we will carry out partial spatial autocorrelation analysis. Moran scatter plot is one of the main methods of partial spatial autocorrelation analysis.

Coordinate points of Moran scatter plot are $(x, W x)$, linear relationship of $x$ and spatial lag factor $W x$ carries on visualized 2D drawings. Because the weight matrix is standardized, it represents a weighted average of the neighboring region observations. Moran scatter plot divides the entire space contact into four quadrants, respectively to the four types of local spatial connection mode between provincial region and its adjacent areas: HH: high-high correlation, corresponding to the first quadrant, representing the spatial correlation model of the high observations units surrounded by high observations units; LH: low-high correlation, corresponding to the second quadrant, representing the spatial correlation model of the low observations units surrounded by high observations units; LL: low-low correlation, corresponding to the third quadrant, representing the spatial correlation model of the low observations units surrounded by low observations units; HL: high-low correlation, corresponding to the fourth quadrant, representing the spatial correlation model of the high observations units surrounded by high observations units. Quadrant I and III represent the positive spatial correlation, revealing gathering area and similarity. Quadrant II and IV indicate that there is a strong spatial negative correlation and regional heterogeneity. Therefore, Moran scatter plot identifies the local spatial agglomeration type of the units belonged to.

Figure 3 and Figure 4 respectively show Moran scatter plot of patents granted of innovation output in 2004 and 2013.

Figure 3, Figure 4 and Table 3 show that patents granted generally exhibit spatial positive in China. Among them, in 2004, the provinces in the first and third quadrant accounted for $70.97 \%$, furthermore, there are $45.16 \%$ in the first quadrant, showing $\mathrm{HH}$ relevant, 25.81\% in the third quadrant, showing LL relevant. In 2013, there are $77.42 \%$ of the province in the first and third quadrant, showing the positive spatial correlation, and the first quadrant $\mathrm{HH}$ correlation was $45.16 \%, 32.26 \%$ is in the third quadrant ,showing LL relevant. Contrast these data of 2004 and 2013, innovation agglomeration of China further strengthen in 2004-2013. Provinces with HH correlation are relatively stable, but provinces with LL correlation increase, indicating that while innovation capacity is rapidly increasing in China, some areas have poor innovation ability and no strong areas to rely on, leading to LL correlation rising. In addition, Moran scatter plot can also identify regional instability and atypical space,

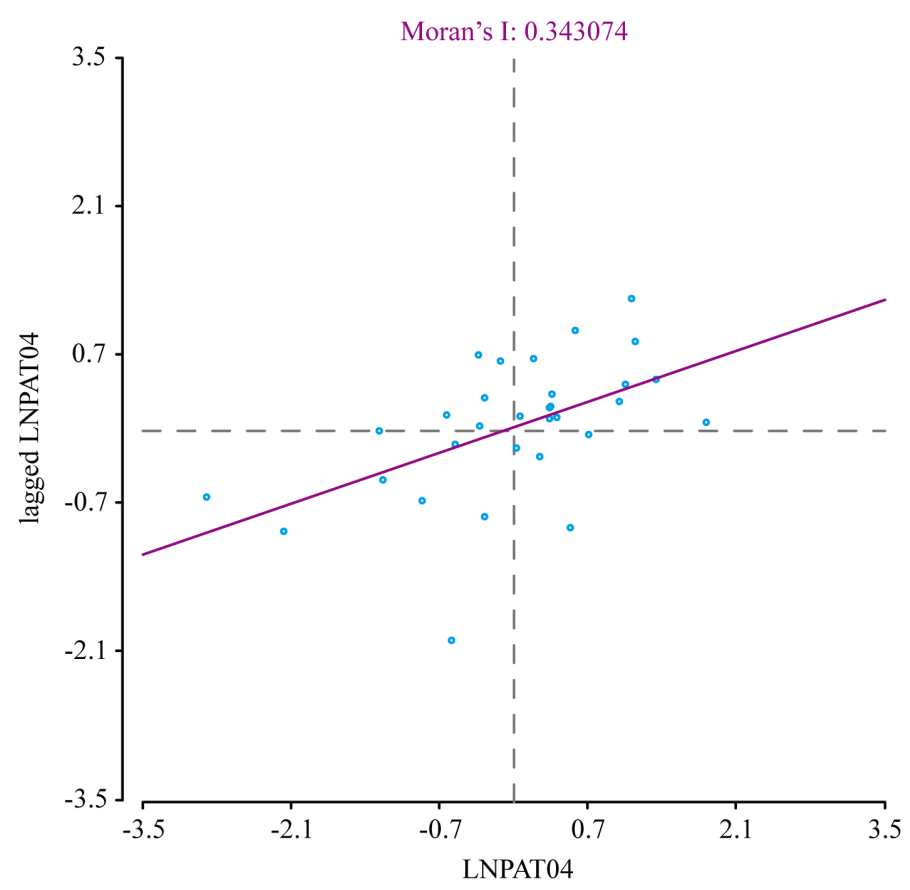

Figure 3. 2004 Moran scatter plot of patents granted. 


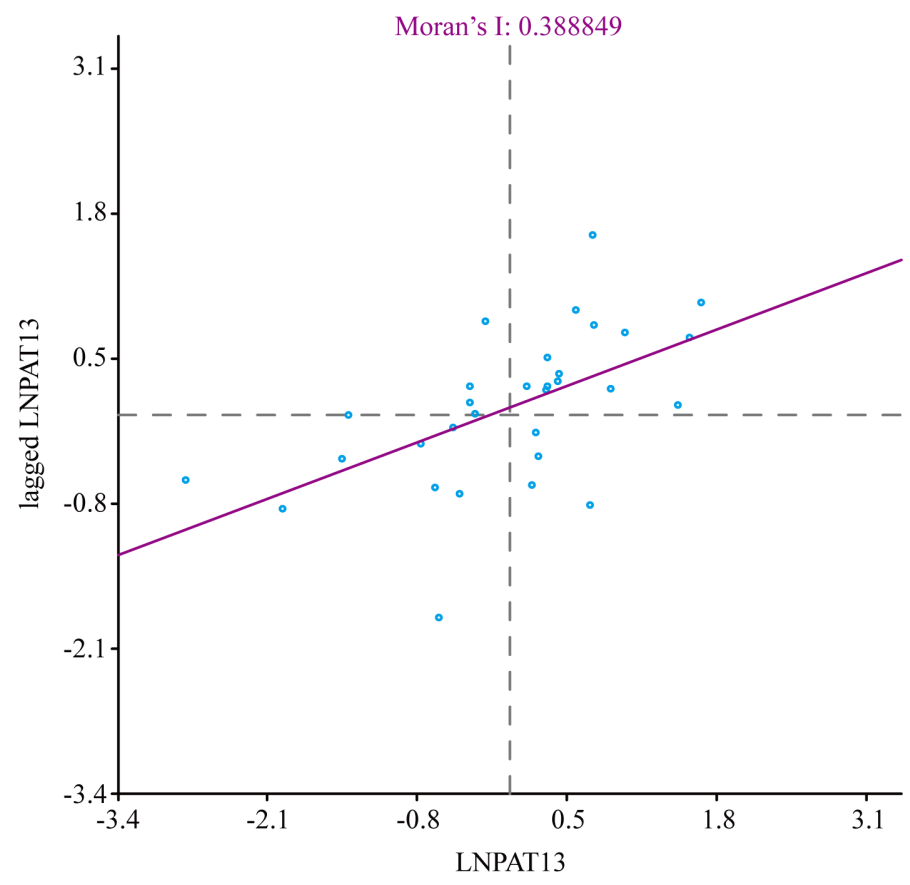

Figure 4. 2013 Moran scatter plot of patents granted.

Table 3. 2004 and 2013 spatial correlation model of China’s regions.

\begin{tabular}{cccccc}
\hline Province & LNPAT04 & LNPAT13 & Province & LNPAT04 & LNPAT13 \\
\hline Beijing & HH & HH & Hubei & HH & HH \\
Tianjin & HH & HH & Hunan & HH & HH \\
Hebei & HH & HH & Guangdong & HH & HH \\
Shanxi & LH & LL & Guangxi & LH & LH \\
Inner Mongolia & LL & LL & Hainan & LL & LL \\
Liaoning & HL & HL & Chongqing & HH & HH \\
Jilin & HH & LL & Sichuan & HL & HL \\
Heilongjiang & HL & HL & Guizhou & LH & LH \\
Shanghai & HH & HH & Yunnan & LL & LL \\
Jiangsu & HH & HH & Tibet & LL & LL \\
Zhejiang & HH & HH & Shanxi & HL & HL \\
Anhui & LH & HH & Gansu & LL & LL \\
Fujian & HH & HH & Qinghai & LL & LL \\
Jiangxi & LH & LH & Ningxia & LL & LL \\
Shandong & HH & HH & Xinjiang & LL & LL \\
Henan & HH & HH & & & \\
\hline & & & &
\end{tabular}

that is, the areas are different from the positive spatial correlation pattern. There are nine provinces in 2004 showing negative space, of which five provinces in the second quadrant, four provinces in the fourth quadrant. There are seven provinces in 2013 showing negative space, of which three in the second quadrant, four in the 
fourth quadrant. As can be seen from the data, the provinces located in negative space, contrary to the general pattern, are less and less. In the scatter plot of two years, Jiangxi, Guizhou and Guangxi are always in the second quadrant, LH correlation, representing low observation is surrounded by high observation, indicating their surrounding have good performance, but their own have poor performance, perhaps they should look for their own reasons. And Heilongjiang, Shaanxi, Sichuan and Liaoning has been in the fourth quadrant, representing due to their own reasons and policy development, although surrounded by low innovation capacity, they show a good trend of innovation.

\section{Spatial Econometrics Analysis of Innovation Agglomeration}

\subsection{Index Selection and Data Sources}

\subsubsection{Explained Variables}

There are many measuring indicators of innovation output, but the most commonly used is the two ways: the amount of patents granted and technology markets transactions contract amount. Considering some innovation output are not be traded in the market and there is a lot of innovation output are traded, having a certain amount, but innovation output may not be able to fully market oriented, so the technology market transactions contract amount may not reflect all the innovation output of the year. In view of this, this paper uses patents granted of innovation output in 2004-2013 as explained variables, because it reflects the true level of innovation output. Since the absolute data is too large, the paper data for all indicators have taken on logarithmic form, to reduce the error caused due to the different size.

\subsubsection{Explanatory Variables}

1) Gross Domestic Product: GDP. This paper selects GDP of China's regions as an explanatory variable of patents granted. The patent level is closely related to GDP, GDP is often higher, the more the number of its patent.

2) R\&D capital investment: R\&DEXP. In this paper, R\&D capital investment of 10 years is selected as another explanatory variable of innovation output, because the number of R\&D investment is closely related to the size of innovative output.

3) R\&D personnel investment: R\&DPER. In other conditions remaining unchanged, the number of $R \& D$ person and innovation output may show positive correlation.

\subsubsection{Data Sources}

The data of China's 31 provinces are particularly from the "China Statistical Yearbook" and "China Statistical Yearbook on Science and Technology” in 2004-2013.

\subsection{Model}

Spatial econometric models are mainly spatial lag model, spatial error model and spatial Durbin model, etc. Spatial Durbin model is a general form of spatial lag model and spatial error model. Without loss of generality, the model is set to spatial Durbin model. Due to the use of panel data, the model finally is set to spatial panel Durbin model:

$$
\begin{aligned}
L_{N P A T_{i t}=} & c+\delta \sum_{j=1}^{31} W_{i j} L N P A T_{i t}+\alpha_{1} L N G D P_{i t}+\beta_{1} L N R \& D E X P_{i t} \\
& +\gamma_{1} L N R \& D P E R_{i t}+\alpha_{2} \sum_{j=1}^{31} W_{i j} L N G D P_{i t}+\beta_{2} \sum_{j=1}^{31} W_{i j} L N R \& D E X P_{i t} \\
& +\gamma_{2} \sum_{j=1}^{31} W_{i j} L N R \& D P E R_{i t}+\varepsilon_{i t}
\end{aligned}
$$

In this model, the subscript $i$ and $t$ denote the year $t$ of region $i ; \varepsilon_{i t}$ is independent and identically distributed random error term with zero mean and $\sigma^{2}$ variance, $W_{i j}$ is weight matrix, the same meaning as above. This model takes influences of the spatial lag explained variables and explanatory variables to explained variables into account, but in order to simplify the analysis, this is not considering the spatial effect and the time effect, so the 
model is set to a mixed panel data.

\subsection{Empirical Results Analysis}

According to 10-years data of China's 31 provinces, the paper uses maximum likelihood to estimate spatial Durbin model above in Stata. Results are in Table 4.

Overall, the fitting effect of model is better, $R^{2}$ is 0.928 . What's more, as column (1), the gross domestic product, R\&D capital investment and R\&D personnel investment have invested a positive impact on innovation output. GDP and R\&D personnel investment is significant in the $1 \%$ significance level, and other conditions remaining unchanged, when the growth of GDP is $1 \%$, innovation output increases $0.752 \%$. The same investment in R\&D personnel per $1 \%$ makes innovation output increase $0.484 \%$. But the impact of R\&D capital investment did not pass the significance test, this conclusion is not consistent with reality, due to improper data handling.

Column (2) shows the influence of GDP, R\&D investment of surrounding provinces to innovation output of the province. It can be seen from the list, the results are not significant, indicating that the relationship is not close between GDP and R\&D investment in the province and innovation output in neighboring provinces.

In column (3), results obtained are significant in the $1 \%$ significance level, indicating that innovation output in neighboring provinces and the province's innovation output are closely related. Innovation output exhibits positive spatial autocorrelation. The regions of strong innovation capacity usually are surrounded by the same ones, indicating location factors have a strong influence on innovation output, so innovation exhibits spatial agglomeration characteristics.

Table 4. Empirical results. xsmle lnpat lngdp lnrdexp lnrdper, wmat (WWW) model (sdm) Durbin (lngdp lnrdexp lnrdper) robust nolog.

\begin{tabular}{|c|c|c|c|c|c|c|c|}
\hline \multirow{2}{*}{ VARIABLES } & (1) & (2) & (3) & (4) & (5) & (6) & (7) \\
\hline & Main & Wx & Spatial & Variance & Direct & Indirect & Total \\
\hline \multirow[t]{2}{*}{ lngdp } & $0.752^{* * * *}$ & -0.167 & & & $0.753^{* * *}$ & 0.106 & $0.859^{* *}$ \\
\hline & $(0.230)$ & $(0.421)$ & & & $(0.187)$ & $(0.444)$ & $(0.432)$ \\
\hline \multirow[t]{2}{*}{ lnrdexp } & 0.112 & 0.0314 & & & 0.131 & 0.0754 & 0.206 \\
\hline & $(0.197)$ & $(0.247)$ & & & $(0.208)$ & $(0.313)$ & $(0.360)$ \\
\hline \multirow[t]{2}{*}{ lnrdper } & $0.484^{* *}$ & -0.111 & & & $0.474^{* *}$ & 0.00821 & 0.482 \\
\hline & $(0.216)$ & $(0.251)$ & & & $(0.229)$ & $(0.302)$ & $(0.340)$ \\
\hline \multirow[t]{2}{*}{ rho } & & & $0.289^{* * *}$ & & & & \\
\hline & & & $(0.0657)$ & & & & \\
\hline \multirow[t]{2}{*}{ lgt_theta } & & & & $-1.472^{* * * *}$ & & & \\
\hline & & & & $(0.260)$ & & & \\
\hline \multirow[t]{2}{*}{ sigma_e } & & & & $0.0556^{* * * *}$ & & & \\
\hline & & & & $(0.0117)$ & & & \\
\hline \multirow[t]{2}{*}{ Constant } & $-5.004^{* * * * *}$ & & & & & & \\
\hline & $(0.537)$ & & & & & & \\
\hline Observations & 310 & 310 & 310 & 310 & 310 & 310 & 310 \\
\hline R-squared & 0.928 & 0.928 & 0.928 & 0.928 & 0.928 & 0.928 & 0.928 \\
\hline Number of diqu & 31 & 31 & 31 & 31 & 31 & 31 & 31 \\
\hline
\end{tabular}

Robust standard errors in parentheses. ${ }^{* * *} \mathrm{p}<0.01,{ }^{* *} \mathrm{p}<0.05,{ }^{*} \mathrm{p}<0.1$. 


\section{Conclusions and Policy Recommendations}

Economic geographers believe that geographical relevant statistics have space-dependent characteristics in spatial distribution, that is, the value of a property in an area is affected by the surrounding area, which mainly dues to first geography law: in geographic space adjacent phenomenon is more similar than the distant phenomenon [15]. In the study of the influences of R\&D activities on innovation distribution, researchers find that knowledge spillovers lead to spatial agglomeration of innovation distribution. This paper uses 10-years data of China's 31 provinces to analyze innovation agglomeration. Firstly, the innovation output has agglomeration effect in the space. The visual map of China shows the spatial distribution of innovation: innovation output of the eastern regions accounts for two-thirds, the gap of eastern and western areas of innovation output is gradually widening. Secondly, this paper analyzes spatial autocorrelation with the knowledge of spatial statistics. Furthermore, Moran's I index and scatter plot from global and local analyze the polarization effects of innovation. Moran's I index shows that the geographic differentiation phenomenon is not randomly generated, but the result of positive space-related. Spatial agglomeration of innovation output on the global and local exhibits strong spatial dependence characteristics. Finally, the spatial Durbin model empirically analyzes innovation spatial agglomeration factors. The results showed that the geographic location factors significantly affect innovation, and innovation output will grow as GDP and R\&D investments are increasing.

Policy implications of this paper is that innovation policy makers not only consider their own factor conditions, but also make full use of innovation agglomeration, location advantages, knowledge spillovers, spatial dependence and other geographical conditions in formulating regional innovation policy to increase regional exchanges, expand the scope and intensity of innovation radiation and realize win-win. Especially in the Midwest regions, they can send technical personnel to leading innovation regional to learn or make the projects with significant impact on the regional economic development settled into the leading technology region and establish R\&D bases to achieve rapid growth in the innovation output.

\section{References}

[1] Wu, Z. (2010) Research on the Spatial Distribution and Spatial Association of Innovation Agglomeration. Economics and Management of Technology, No. 3, 38-41.

[2] Ashaeim, B.T. and Location, I.A. (1997) Agglomeration and Innovation: Towards Regional Innovation Systems in Norway? European Planning Studies, 5, 299-330. http://dx.doi.org/10.1080/09654319708720402

[3] Landan, R. and Rosenberg, N. (1986) The Positive Sum Strategy. National Academic Press, Washington.

[4] Jung, H.K. (2001) The Role of Two Agglomeration Economics in the Production of Innovation: A Comparison between Localization Economics and Urbanization Economics. Enterprise and Innovation Management Studies, 2, 103117. http://dx.doi.org/10.1080/14632440110083373

[5] Song, Q., Han, B.T. and Li, Y. (2010) A Review of Researches on Innovative Clusters. Science Progress and Policy, 27, 157-160.

[6] Zhao, J.J. and Zeng, G. (2009) Spatial Measurement of Innovation: Data and Indicator. Economic Geography, 29, 1250-1255.

[7] Liu, F.C., Yang, L. and Sun, Y.T. (2011) The Spatial Concentration of Innovation and Its Mechanisms and Factors: A Literature Review on Foreign Research. Management, 8, 1413-1418.

[8] Wu, Y.M. (2006) A Spatial Econometric Model and Its Application to Research \& Development and Regional Innovation. Quantitative Economics Technology Research, 5, 74-130.

[9] Zhang, L.H. and Lin, S.L. (2010) Research on the Correlation between Innovation Agglomeration and Industrial Agglomeration. Science Studies, 28, 635-640.

[10] Li, J. (2013) Spatial Econometrics Analysis on the Integration of Region Innovation-Evidence Form China. Industrial Technology \& Economy, 11, 138-148.

[11] Li, J., Tan, Q.M. and Bai, J.H. (2010) A Spatial Analysis of Chinese Regional Innovation Production-An Empirical Study Based on the Static and Dynamic Spatial Panel Model. Management World, 7, 43-65.

[12] Zhang, Y.M. and Li, K. (2008) Research on the Spatial Dependence of Chinese Province-Level Innovative Output. Science Studies, 26, 659-665.

[13] Luo, F.Y. (2004) Studies of Spatial Distribution Characters and Its Causes of Chinese Innovation Output. Learned Journal of Hunan University of Science and Technology (Social Sciences), 7, 76-81.

[14] Han, J., Song, T., Chen, C.F. and Qu, G. (2013) Research on Regional Innovation Efficiency Based on Green Growth 
in China. Economic and Social Systems Comparison, 3, 100-110.

[15] Li, Z.G., Tang, S.K., Liang, X.Y. and Wu, L.G. (2006) Research on the Spatial Distribution of Chinese Innovative Output: Spatial Econometrics Analysis Based on Province-Level Patent Data. The Management of Science and Science Technology, 8, 64-71. 